\title{
Digital Technologies as a Factor in the Development of Modern Marketing
}

\author{
Nadezhda Arkhipova \\ Russian State University for Humanities \\ Moscow, Russia \\ 2506539@mail.ru
}

\author{
Alan Abaev \\ Department of Marketing and Advertising \\ Russian State University for Humanities \\ Moscow, Russia \\ abaeval@rggu.ru
}

\author{
Madina Gurieva \\ Department of Marketing and Advertising \\ Russian State University for Humanities \\ Moscow, Russia \\ gurieva.m@rggu.ru
}

\begin{abstract}
The article analyzes certain aspects of the digital transformation that is currently taking place in marketing communications all over the world. The widespread availability of digital technologies, the time consumers worldwide spend in a digital environment and the shift in customers' expectations in terms of personalization of communications are inevitably influencing the way companies address their clients and the communication channels they use. The companies will be forced to adjust their own structures and management priorities to fit these processes.
\end{abstract}

Keywords—digital marketing; marketing communications; customer communications; digital transformation

\section{INTRODUCTION}

The modern approach to electronic marketing and digital marketing is relatively wide. In spite of the fact that terminology has not been completely established, there is a general understanding that this development of marketing technologies has a huge potential. The term "digital marketing" meaning "products and services marketing through utilization of digital technologies" has been in active use since the 1990s and the beginning of the 2000s, and is connected with the development of Internet and Internet marketing instruments. However, it is not limited to the Internet technologies. According to numerous professional opinions, what is called electronic marketing today existed long before the Internet and relevant technologies. Digital marketing is, in a wider sense, any type of marketing where electronic devices are used. This understanding widens the time boundaries of digital marketing's existence and usage to approximately a century, beginning about 1910 . It was then, only a few years after the invention of radio, the first opera radio broadcast from the Metropolitan took place, resulting in many people buying tickets to the opera for the first time in their lives. This example clearly indicates that the terms "Internet marketing" and "digital marketing" are not synonymous and that electronic marketing is a much more wide-scale phenomenon although it is currently largely represented by Internet marketing and its instruments. The most active period of the digital marketing development is connected mainly with the spread of the Internet and with the consequent changes in consumer behavior, needs, and expectations.

\section{SHIFTS IN CONSUMER BEHAVIOR AND EXPECTATIONS LEADING TO SPREADING OF DIGITAL MEDIA}

The most important reasons for the current situation whereby electronic marketing is the focus of attention of companies of all sizes and spheres are the following:

- The consumers' move to digital channels.

- The possibilities of targeting.

- The possibility to obtain and process huge amounts of consumer information and to create an offer that would be completely adapted to their specific needs.

\section{A. The Consumers' Move to Digital Channels}

In speaking about consumers' move to digital channels, it would be too early to proclaim the "death" of television, press, and outdoor advertising in general. For example, at the present time, press advertising remains the main communications mode for the majority of luxury products and brands. However, the general trend is very obvious: the consumer spends more and more time in a digital environment. A 2014 study by Nielsen showed that the average US citizen, aged 18 and older, spends more than 11 hours per day in some kind of electronic environment or with an electronic device (including television, radio, Internet on a PC, smartphones, play stations, and similar items) [1]. It must be understood that this is not a complete immersion for all of the time; for example, sometimes the electronic devices 
are switched on when a person is occupied by other activities. However, taking into consideration only 16-18 hours per day are left when we presume 6-8 hours of sleep, 11 hours in the digital environment is a substantial amount. The consumption of electronic media increased by at least $40 \%$ since 1985 . The consumer is constantly connected to a digital environment. In spite of all regulations and bans, about 9 per cent of all people who are driving at any moment are using their smartphones (talking or even texting) [2]. Obviously, the percentage of their passengers that are using such devices is even higher. When considering that the prospect of driverless cars is realistic for the near future, it is possible that outdoor advertising has really outlived itself. (Taking into consideration companies such as Google and Apple are actively involved the development of this technology, it is possible to question the time frame, but not the outcome.) Both the "drivers" and the passengers will be equally immersed in the digital environment and will pay little or no attention to the roadside billboards.

Those trends are relevant for the Russian market as well. In 2016, Russian citizens aged 4 years and older, spent an average of 248 minutes per day watching television. The youngest age group (4-17 years old) spent the smallest amount of time on TV, 132 minutes per day, while the oldest group (65 years old and above) spent 402 minutes per day. The average TV watching time per day has increased since the previous study of 2012 by 10 percent [3].

87 million Russian citizens (71 percent of the relevant age groups) have Internet access and 66 million access the Internet through their mobile devices. The number of smartphone users is increasing faster than the number of other devices' users. Data from the beginning of 2017 shows that this number increased by 15 percent (year to year) while the number of users accessing the Internet from their desktop and laptop computers went down by 4 percent. According to Mediascope WEB-Index (March 2017), a resident of a large Russian city spends an average of 237 minutes per day on the Internet and approximately half of this time, it is mobileaccessed. The younger generation is relatively more "mobilized" - the 12-24 age group spends about 138 minutes per day browsing on the Internet from mobile devices, while the 35-64 age group uses mobile devices to access the Internet for only 98 minutes [4]. Clearly, this trend will remain in place and become even stronger in the future as current teenagers become older. At the end of 2016, Validata research company conducted (for Sberbank) extensive research of the Russian young generation, the "centennials". The researchers described a salient characteristic: "They were born with a finger on the button." The online sphere is reality for this generation: they feel much more at ease when they get acquainted, share their thoughts and values, make purchases, and search for information on the Internet. Their trends and role models are also on the Internet. It is very important for these youths to be continually available to their friends, to keep in contact, something which has become possible precisely due to the mobile devices accessing the Internet. Consequently, communications and marketing in general have to take into consideration the young peoples' way of thinking [5].
It is obvious therefore, that the companies have to follow their consumer - and their consumer is spending more and more time in the electronic environment and is less and less reachable through traditional communication channels.

\section{B. The Possibilities of Targeting}

It is the possibility of using specific criteria in order to select a certain part of the audience and address this part more efficiently. Traditional TV and press advertising undoubtedly has wide coverage; that is one of its advantages. However, in spite of all the media planning efforts, traditional advertising also reaches a part of the audience that has no interest in the offer. Modern consumers are accustomed to personalized offers and easily ignore everything that does not correspond to their interests. This new consumer feels a need to be in control of everything concerning his personal life and does not approve of "intruders" with an uninteresting content. That is exactly what happens whenever they are watching television ads and - judging by their content - one is young and full of vitality but has a flu, suffers from diabetes but eats lots of candies and cookies, and spends all their time with friends but changes baby diapers - all at the same time. In every situation, it is clear that at least part of the ad (and budget) is lost on the prospective customers. In the worst case scenario, it can become repulsive from the customer's point of view. The marketers have no way to know who will see the ad; they can only measure the quantity of viewers.

Digital marketing instruments raises targeting to a new level and helps to avoid contacting the wrong audience by reaching only potential clients. This is not only about basic demographic characteristics; digital marketing can target certain personality types, customers' values, and interests.

\section{The Possibility to Obtain and Process Huge Amounts of Consumer Information and to Create an Offer that Would Be Completely Adapted for Their Specific Needs}

Such a possibility is a rather new development but it has already proven its efficiency. Using contemporary instruments of marketing analytics, big data companies can accumulate and process endless information concerning the clients, their demographic and behavioral characteristics, their relationship with the brand, the way they makes their purchase decisions, their previous queries and searches, competitive brands offers they had seen, etc [6]. These instruments make it possible to make the most relevant offer in the most comfortable way at a precise moment. Moreover, it is exactly what the client expects today - that the company knows and remembers their preferences and is prepared to offer the expected level of service when and where they need it. The clients become irritated when they are offered the "wrong" information. They feel that this behavior shows lack of attention to detail - like when they keep getting promo coupons for disposable diapers when their child already goes to school.

The above factors are the main reasons why digital marketing is getting so much attention and is present both in the online and offline environments. Even in the offline 
environment, digital technologies are used to increase the efficiency of traditional marketing instruments.

\section{Digital MARKETING TeChNOLOGIES OfFline OPPORTUNITIES}

The following categories currently represent digital marketing online:

- Search Engine Optimization (SEO)

- Search Engine Marketing (SEM)

- Content Marketing

- Social Media Marketing (SMM)

- Pay-Per-Click Advertising (PPC)

- Affiliate Marketing

- E-mail Marketing

These are the categories in digital marketing attracting the most attention. Meanwhile, the use of digital technologies in the offline environment also deserves special attention because it is here the traditional and electronic technologies are used jointly, leading to improved results. The following spheres deserve attention:

- The "enhanced offline marketing", i.e. usage of digital technologies in combination with traditional marketing to enhance consumer experience and satisfaction. Almost any application of the digital media to traditional marketing can be added to this group: electronic LED billboards that attract much more attention than traditional ones, interactive electronic displays set into restaurant tables or the use of iPads to order food, virtual reality devices used to buy clothes without trying them on or buying real estate that is still unbuilt, product demos when selling any type of electronic gadgets (like Apple stores worldwide), and product sampling in the digital format (for products like games, apps, and music). All of the above significantly enhance the brand image and the client's experience.

- Radio marketing. Despite the fact that radio was probably the earliest electronic media used for marketing purposes, it is still actively used. In the USA, radio is the third most powerful medium, reaching 54 per cent of the population daily, while 44 per cent listens to the radio online. Due to the omnipresence of radio, every American listens to an average of 104 minutes daily and it remains one of the most powerful communication channels in the US, generating approximately 4 billion USD in profits. The Russian market is also showing signs of radio retaining its potential. 40 million people listen to the radio on a daily basis, with average listening times ranging from 135 to 192 minutes per day. 80 per cent of the radio audience listens to the radio in their cars so, taking into consideration that people in Russia are spending more and more time commuting, radio remains an important medium. In the first quarter of
2017, radio advertising budgets rose by 8 per cent compared to the first quarter of 2016 [7].

- Phone marketing or, more correctly in the current era, mobile marketing. Traditional telephone marketing is disappearing. In 2014, for the first time ever in the US, the number of people who accessed the Internet from their smartphone outnumbered those accessing the Internet from their desktop or laptop computers. Forecasts show that the budgets for mobile advertising can surpass television advertising budgets as early as 2020, which would correspond to the young peoples' preferences and lifestyles. There are two main factors: First, the young persons' habit to never be away from their smartphones and to always be accessible for their family and friends. Second, they are prepared to receive information in small portions. According to the Validata study, typical members of Generation $\mathrm{Z}$ can concentrate their attention on one object for a maximum of 8 seconds and the visual component is crucial (icons, pictures, emoticons). This characteristic of their generation explains the phenomenon of simple text messages being still relevant for communication purposes. While MMS became practically useless in the mobile Internet era, the short message services are successfully utilized by the companies for client communications. If the client's prior permission has been obtained, more than 95 per cent of all text messages are read and 90 percent are read within the first three minutes of receiving them [8]. That makes texts a convenient part of customer loyalty programs. Specially designed apps that allow the client to accumulate points and receive promos are another part of such programs.

\section{COMPANIES'READINESS FOR THE DIGITAL TRANSFORMATION}

It is clear that a company's ability to fully utilize electronic channels and their possibilities to serve its clients depends on the company's own readiness to change its structure and management mechanisms to implement a digital transformation.

The following capabilities can be reviewed to match digital marketing needs: strategic approach, performance improvement process, management involvement, resources and structure, data and infrastructure, integrated customer communications, and integrated customer experience.

The research conducted in the beginning of 2017 by Smart Insights demonstrates that there are five levels to describe a company's readiness to implement digital marketing, from initial to optimized levels [9]. The company questioned marketing professionals from 609 companies (mostly from the US and the UK) representing various spheres such as marketing, advertising, IT, retail, consulting, finance, government, education, and others. The respondents worked at various levels of management (from marketing assistant to president and/or CEO) to provide a more balanced view. Each level can be characterized as follows: 
The initial level is marked by the absence of a marketing strategy and KPIs; limited management involvement; limited or absent client database; and with unintegrated customer communications and no website. 19 to 30 percent of respondents rated their company's level as initial.

The second level companies show prioritized marketing activities; volume-based KPIs; some verbal support but inadequate resources from management; data, tools, and IT services still separated; partly synchronized communications; and some desktop and mobile support but without personalization. According to the research, this is the level of 32 to 40 percent of the companies (depending on their specific capabilities).

The third level has a defined vision and strategy in terms of a strategic approach; quality-based KPIs; management sponsorship and increased investment; partially integrated systems and data; and an integrated approach to customer communications with partially personalized desktop and mobile experience. This level was claimed by 20 to 30 percent of respondents.

On the fourth level, companies have implemented a business-aligned strategy and roadmap; value-based KPIs; active championing and appropriate investment; integrated systems and data sources; and integrated and personalized customer communications as well as web, mobile, email and social media communications. Only $10-12$ percent of the participating respondents identified themselves as being at this level.

The optimized level is marked by an agile strategic approach; lifetime-value KPIs; digital approaches becoming an integral part of strategic development; a flexible approach to optimize resources in terms of data and infrastructure; media resources optimized for high ROI and full contextual personalized experience; and recommendations in terms of integrated customer experience. In the study, this level has not been reached by more than 3 to 9 percent of the companies.

The problem of digital marketing planning continues to be of great importance. 34 percent of the companies have fully integrated their traditional and digital marketing strategies. 19 percent have a specific digital marketing strategy defined in a separate document while 49 percent are using digital marketing without any type of clearly-defined strategy. Meanwhile, 44 percent of the respondents confirmed the absence of any marketing strategy for their companies.

These companies often conduct uncoordinated communications campaigns without any long-term planning. Such an approach is dangerous in terms of over-inclining to new technological developments offering an increase in efficiency in the short run but lacking long-term brand promotion. Targeting and other opportunities provided by digital marketing have to be viewed cautiously, without making them substitutes for adequate brand-customer communications. It is also important to remember that sometimes big data-based sales promotions can conflict with the brand image. Therefore, the problem of coordinating the efforts of marketers, IT specialists, and other departments becomes more important in terms of increased possibilities for customer behavior research, big data accumulation and analysis, and using digital technologies for marketing activities [10]. In this case, the message reaching the customer through all types of channels should be relevant and clearly defined. Thus, the use of digital media will be beneficial in each of the three stages of company-client interactions: obtaining and accumulating customer information through all the channels; processing vast amounts of data for better understanding of client's needs and interests; and personalized client communications based upon a new level of understanding.

\section{CONCLUSION}

The current state of society in terms of penetration by digital technologies, and people's (especially young people's) involvement in digital media opens a whole range of new possibilities for marketing and, at the same time, makes it impossible to ensure efficient client communications without such technologies. This is true for Russian society as well as for other countries. However, the companies have much to accomplish in order to optimize their structure and procedures for digital transformation, if they are to coordinate the efforts of marketers, IT-specialists, and other departments to coordinate digital technologies with marketing strategies.

\section{REFERENCES}

[1] The Total Audience Report. [Electronic Resource] - The URL: http://www.nielsen.com/us/en/insights/reports/2015/the-totalaudience-report-q4-2014.html

[2] Official website of the National Safety Council. The URL: http://www.nsc.org/DistractedDrivingDocuments/CPK/AttributableRisk-Summary.pdf

[3] Official website of the Association of Communication Agencies of Russia. The URL: http://www.akarussia.ru/

[4] Mediascope Web Index Report 2017 3. [Electronic resource]. The URL: $\quad$ http://mediascope.net/services/media/mediaaudience/internet/information

[5] 30 Facts on Modern Youth. [Electronic Resource] - The URL: http://www.sberbank.ru/common/img/uploaded/files/pdf/youth_prese ntation.pdf

[6] David C. Edelman, Marc Singer. Competing on Customer Journeys, in Harvard Business Review, November 2015. [Electronic resource] The URL: https://hbr.org/2015/11/competing-on-customer-journeys

[7] U.S. Radio Industry - Statistics \& Facts. [Electronic Resource] - The URL: https://www.statista.com/topics/1330/radio/

[8] Mobile Marketing Engine Site. The URL: http://mobilemarketingengine.com/23-mobile-marketing-stats/

[9] Dave Chaffey, Robert Jones, Managing Digital Marketing in 2017. [Electronic resource] http://www.smartinsights.com/managing-digitalmarketing/marketing-innovation/digital-marketing-trends-2016-2017/

[10] Aditya Joshi, Eduardo Jimenes, Decision-Driven Marketing, in Harvard Business Review, July-August 2014. [Electronic resource] The URL: https://hbr.org/2014/07/decision-driven-marketing. 